Study Report 2000-03

\title{
Analysis of the Revised Army Career Transitions Survey (ACTS) and Comparison With the Fall 1996 Sample Survey of Military Personnel (SSMP): Results and Recommendations
}

\author{
Robert A. Giacalone \\ University of North Carolina - Charlotte
}

\section{Army Personnel Survey Office Morris P. Peterson, Chief}

U.S. Army Research Institute for the Behavioral and Social Sciences 5001 Eisenhower Avenue, Alexandria, Virginia 22333-5600

April 2000

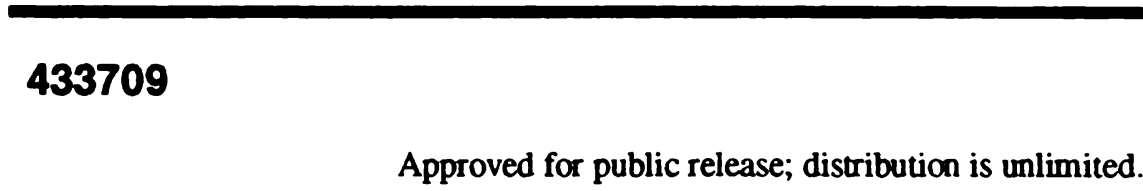

Approved for public release; distribution is unlimited. 